\title{
Enhanced performance of PEM fuel cell using MWCNT reinforced carbon paper
}

Received 13th February 2014 Accepted 7th May 2014

DOI: $10.1039 / c 4 r a 01272 k$

www.rsc.org/advances

\begin{abstract}
Priyanka H. Maheshwari* and R. B. Mathur
Porous conducting carbon paper has been identified as one of the most suitable materials to be used as a fuel cell electrode backing. Carbon paper is prepared by the combined process of papermaking followed by composite formation. Experiments have been carried out whereby heat treated multiwalled carbon nanotubes (MWCNTs) are integrated in the sample while keeping the amount of fiber and resin constant. The diminutive magnitudes of these nanostructures are found to have a considerable effect on the electrical and mechanical properties of the carbon paper electrode. The $I-V$ performance of the unit polymer electrolyte membrane (PEM) fuel cell shows a maximum power density of $880 \mathrm{~mW} \mathrm{~cm}^{-2}$ with 0.05 vol\% of MWCNTs, an increase of $\sim 25 \%$ as compared to $700 \mathrm{~mW} \mathrm{~cm}^{-2}$ obtained using commercially available standard Toray carbon paper tested under similar conditions.
\end{abstract}

\section{Introduction}

Continued reliance on currently used fossil fuels is likely to pose serious environmental and energy supply security challenges. Other types of renewable energy technologies like hydro, wind, solar, tidal and biofuels have lower reliability, low concentration and costly implementation. Fuel cells are predicted to be the clean power delivery devices for the future. They have many advantages such as a wide fuel selection, high energy density, high operating efficiency and an inherent safety which explains the immense interest in this power source. Among the other fuel cells polymer electrolyte membrane fuel cell (PEMFC) is much preferred because of the additional advantage of low operating temperatures and absence of corrosive, liquid electrolyte. ${ }^{1,2}$

The electrode substrate, i.e. the carbon paper is an important component of fuel cell that carries out various critical functions that includes; providing (i) mechanical support to the membrane electrode assembly; (ii) electronic conductivity; (iii) porous media for the catalyst to adhere to; (iv) reactant gas access to the catalyst layers and (v) product removal. Because of its vital role in fuel cell performance, much effort has been directed towards optimizing its properties. ${ }^{3-11}$ Porous conducting carbon paper has been identified as one of the most promising material as the electrode substrate/gas diffusion layer (GDL) support, not only because of its high conductivity that allows easy flow of electrons but also because of its fine porosity that allows uniform distribution of the reactant gases over its surface.

Physics and Engineering of Carbon, CSIR-National Physical Laboratory, New Delhi, India. E-mail: hedap@mail.nplindia.ernet.in; Fax: +91 11 45609310; Tel: +91 11 45608508
In their previous studies the authors have reported a preparation technique of porous conducting carbon paper using a two-step process which involves paper making followed by composite formation. ${ }^{9}$ In the present study the effect of incorporating multiwalled carbon nanotubes (MWCNTs) in the carbon paper sample have been studied. Surprisingly, diminutive amount of these nanostructures show momentous impact on the structure and properties of the carbon paper. A MWCNT is a tubular structure made up of concentrically rolled grapheme sheets with diameter in nanometer range. These have always been an exciting material in terms of its properties like high surface area, high electrical and thermal conductivities, extraordinary strength, resilience and hydrophobic nature. ${ }^{12-14}$ These characteristics, if utilized in a proper manner, can prove functional for improving the performance of fuel cell electrode. Attempts have been made to grow CNTs directly on to the carbon paper to form a GDL ${ }^{15-21}$ and as catalyst support. ${ }^{22-32}$ The present study however targets the carbon paper for enhanced performance using a novel and simple technique of CNT incorporation without any additional cost or elaborate setup. This will go a long way in rendering a cost competitive and industrially viable technology. The incorporated CNTs were heat treated to remove the catalytic impurity. The process was found to have a considerable effect not only on the structure but also on the thermal stability of the $\mathrm{CNTs}^{15}$ which has been discussed in detail. However managing carbon nanotubes poses serious challenges beyond a particular limit (amount), due to difficulties in: (i) dispersion of CNTs because of the strong van der Waals forces and (ii) wetting of the tubes with the resin because of their very high surface area. The consequences of the above configuration on the fuel cell performance with special reference to the different regions of the fuel cell polarization curves have been discussed. 


\section{Experimental}

\subsection{Purification of carbon nanotubes}

Commercially available MWCNT grade Nanocyl 7000 having a diameter of nearly 15-20 $\mathrm{nm}$ and aspect ratio >1000 was used in the experiments. In order to remove the catalyst impurities and enhance its structural stability the MWCNTs so formed were heat treated to $2200{ }^{\circ} \mathrm{C}$ in an inert atmosphere.

\subsection{Characterization of carbon nanotubes}

The amount of catalyst impurity in the pristine and heated nanotube samples was ascertained with the help of thermogravimetric analysis, carried out in air at the rate of $10^{\circ} \mathrm{C} \mathrm{min}^{-1}$ on TGA/DSC 1600 by Mettler Toledo. The TGA curve of the two samples (as shown in Fig. 1) registers a weight loss of $91.2 \%$ and $100 \%$ respectively, thus indicating complete removal of the catalyst impurity from the initial $8.8 \%$. Apart from the catalyst removal, there is a marked increase in the thermal stability of the MWCNTs after heat treatment. As shown by the DTG curves, the decomposition of pristine CNTs takes place at around $610{ }^{\circ} \mathrm{C}$ (Fig. $\left.1 \mathrm{a}^{\prime}\right)$ whilst that of the heated sample takes place at nearly $750{ }^{\circ} \mathrm{C}$ (Fig. $\left.1 b^{\prime}\right)$. Purified tubes were therefore employed in the development of carbon paper so that the catalyst impurity may not interfere with the fuel cell functioning.

The Raman spectra of the pristine and heat treated nanotubes is shown in Fig. 2. The intensities of the bands were determined by the area under the spectral curve. The intensity of the G-band $\left(I_{\mathrm{G}}\right)$ was used as a reference in determining the relative intensities of the $\mathrm{D}$ band $\left(I_{\mathrm{D}}\right), \mathrm{G}^{\prime}$ band $\left(I_{\mathrm{G}^{\prime}}\right)$ and $\mathrm{D}+\mathrm{G}$ $\left(I_{\mathrm{D}+\mathrm{G}}\right)$ band. The large value of $I_{\mathrm{D}} / I_{\mathrm{G}}$ (1.16) for the pristine MWCNTs is indicative of the defects and possibly due to the large number of pentagons and heptagons that form the closed ends of the small sized nanotubes. The process of heat treatment not only removes the $\operatorname{defects}^{33}\left(I_{\mathrm{D}} / I_{\mathrm{G}}=0.27\right)$ but also results in an increased graphitic alignment of the individual CNT walls. This is clear from the values of $I_{\mathrm{G}^{\prime}} / I_{\mathrm{G}}$ that increases from 0.71 for pristine CNTs to 1.45 for the heated ones. The D + $\mathrm{G}$ band is another defect form of nanostructured $\mathrm{sp}^{2}$ carbon

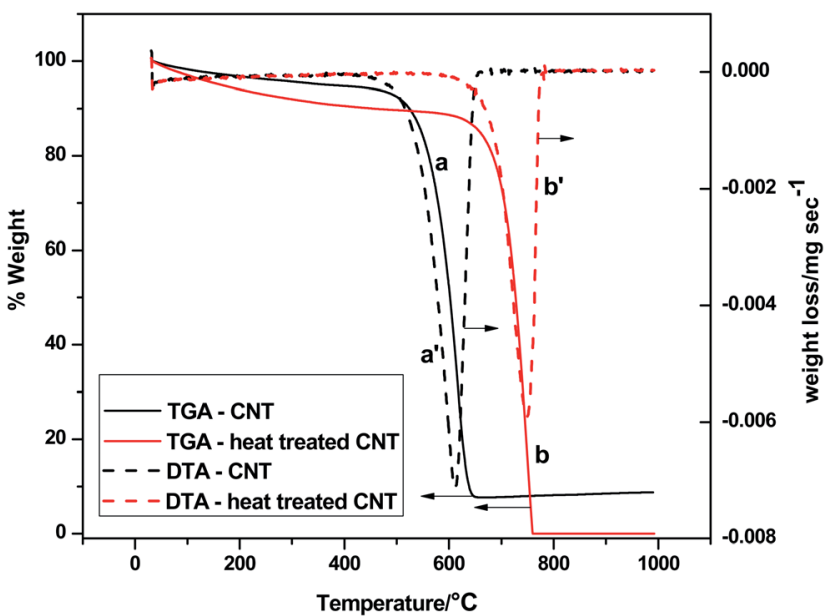

Fig. 1 TGA and DTA curves of pristine and heat treated MWCNT samples.

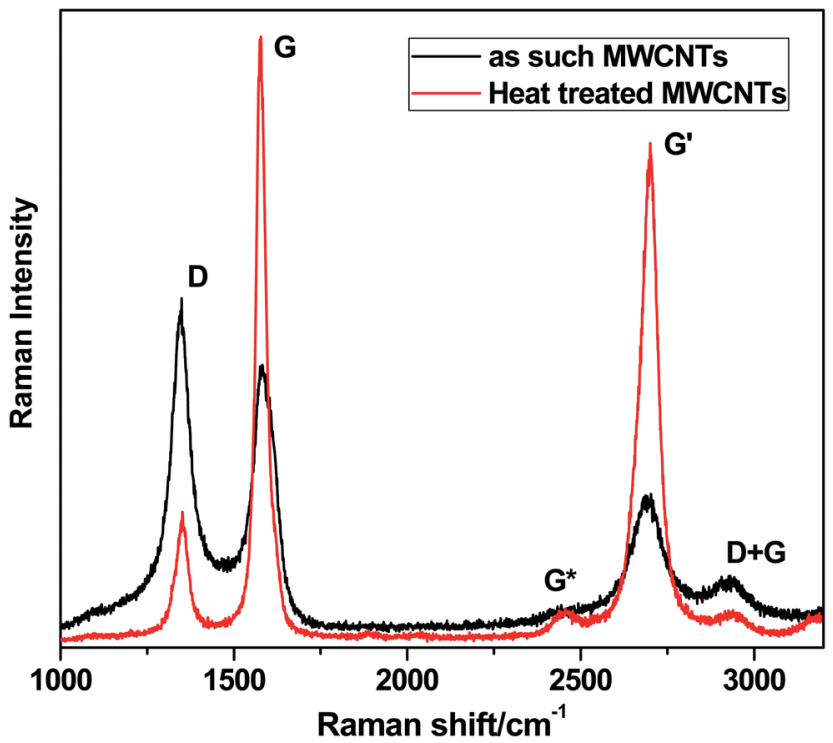

Fig. 2 Raman spectra of pristine and heat treated MWCNT samples.

which may include pentagons with a small content of $\mathrm{sp}^{3}$ bonding. ${ }^{34}$ There is a decrease in the intensity of the $\mathrm{D}+\mathrm{G}$ band by an order of magnitude $\left(I_{\mathrm{D}+\mathrm{G}} / I_{\mathrm{G}}=0.19\right.$ for pristine and 0.018 for heat treated CNTs) which is probably the indication of opening up of the closed CNT ends.

The apparent density of the heat treated CNTs was determined by pycnometric method using kerosene as the pycnometric liquid. An oven dried specific gravity (SG) bottle was weighed as such, and after being filled with pure distilled water. The procedure was repeated with kerosene oil. The ratio of the weight of kerosene oil to that of distilled water multiplied by the density of distilled water gives the density of the kerosene oil used. The oven dried MWCNT sample was placed into the weighed SG bottle, which is then weighed again. The bottle is then partially filled with kerosene oil such that the sample dips well into the oil. The unstoppered bottle is then placed in a vacuum desiccator and evacuated with the help of vacuum pump till no air bubbles are observed. The remaining space is then filled with kerosene oil up to its full capacity and weighed. The apparent density of the material was then calculated as

Density $=$ (weight of the sample/weight of kerosene oil displaced by the sample) $\times$ density of kerosene oil.

The kerosene density of the pristine and heat treated MWCNT sample was found to be $2.038 \mathrm{~g} \mathrm{~cm}^{-3}$ and $1.608 \mathrm{~g} \mathrm{~cm}^{-3}$ respectively. The decrease in the density is probably because of the removal of catalytic impurity with heat treatment.

The BET surface area of the pristine and heated MWCNT samples (determined using Quantachrome iC) was almost same and found to be nearly $315-320 \mathrm{~m}^{2} \mathrm{~g}^{-1}$.

\subsection{Preparation of carbon paper}

Polyacrylonitrile (PAN) based T-300 grade carbon fiber (density $1.76 \mathrm{~g} \mathrm{~cm}^{-3}$ and specific surface area $0.450 \mathrm{~m}^{2} \mathrm{~g}^{-1}$ ); was used for 
making porous carbon fiber preforms, by the well known paper making technique. ${ }^{9}$ The carbon fiber preforms thus prepared were impregnated with phenolic resin (obtained from 'IVP India Ltd') such that the ratio of reinforcement (fiber) to the resin is $1: 1$ by volume. Experiments have been carried out by impregnating the preforms with resin modified by different amounts $(0.02,0.05,0.07$ and 0.1 vol\%) of heat treated MWCNTs. The impregnated preforms were then molded into sheets by compression molding technique. Following molding, a postcure was performed at $150{ }^{\circ} \mathrm{C}$ for 2 hours in air to ensure full curing and cross-linking of the binder material before carbonization. The samples so obtained are known as green samples. These were further heated to $2200{ }^{\circ} \mathrm{C}$ in an inert atmosphere with a heating rate of $900{ }^{\circ} \mathrm{C} \mathrm{h}^{-1}$, and kept on hold for $15 \mathrm{~min}$. at the final temperature. In the following text the carbon papers prepared without MWCNT and with 0.02, 0.05, 0.07 and 0.1 volume \% of MWCNT are designated as samples A, B, C, D and E respectively.

\subsection{Characterization of the carbon paper}

The Flexural strength and modulus of the carbon paper samples were measured on the INSTRON machine model-4411 according to ASTM: D 1184-69.

The in-plane resistivity of the carbon paper was measured using the four-probe technique. The samples were cut into rectangular shape $(5 \mathrm{~cm} \times 2 \mathrm{~cm})$ and dc current of $10 \mathrm{~mA}$ was passed along the length of the sample with the help of Keithley 224 programmable current source. The voltage drop was measured along its length with the help of two probes separated by unit length (i.e. $10 \mathrm{~mm}$ ) using Keithley 197A auto-ranging microvolt DMM. The resistance, $R$ was measured according to Ohm's law $(R=V / I)$. The through-plane electrical resistance was measured using two-probe technique. The paper samples $\left(1 \mathrm{~cm}^{2}\right)$ was placed in between gold coated copper plates with contacts. Constant current of $10 \mathrm{~mA}$ was passed across the cross section of the paper and corresponding voltage drop was measured.

Cyclic voltammetry measurements of the carbon paper samples were carried out to determine the electrochemical surface area (Autolab PGSTAT 302). In the three-electrode method applied, standard calomel electrode (SCE) was used as the reference electrode whereas carbon paper and platinum coil were used as working and counter electrodes respectively. $1 \mathrm{M}$ sulphuric acid was used as an electrolyte since it contains the sulphonic acid group $\left(\mathrm{SO}_{3}{ }^{-} \mathrm{H}^{+}\right)$, which provides charge sites for proton transport in the Nafion membrane used in PEMFC. The scan rate was fixed at $50 \mathrm{mV} \mathrm{s}^{-1}$ and four scans per sample were recorded to attain stable and reproducible voltammograms.

\subsection{Formation of membrane electrode assembly and fuel cell performance}

Gas diffusion layer (GDL) was prepared on the carbon paper samples of size $25 \mathrm{~cm}^{2}$, by coating $1.5 \mathrm{mg} \mathrm{cm} \mathrm{cm}^{-2}$ of carbon black (Vulcan XC-500 obtained from Cabot Corporation, USA) followed by sintering at $350{ }^{\circ} \mathrm{C}$. Catalyst layer was prepared by coating the GDL with $0.5 \mathrm{mg} \mathrm{cm} \mathrm{cm}^{-2} \mathrm{Pt}$ (in the form of $40 \% \mathrm{Pt} / \mathrm{C}$ ) and Nafion (7 wt\% and $30 \mathrm{wt} \%$ of $\mathrm{Pt} / \mathrm{C}$ at anode and cathode respectively). Nafion Membrane-1135 (obtained from E.I. DuPont de Nemours \& Co.) was sandwiched in between the two electrodes (as prepared above) and hot pressed at $120-130{ }^{\circ} \mathrm{C}$ for $3 \mathrm{~min}$. to make the membrane electrode assembly (MEA). Fuel cell was evaluated at $60{ }^{\circ} \mathrm{C}$ and $100 \%$ humidified conditions. Hydrogen (as fuel) and the oxidant stream were supplied at the anode and cathode at a flow rate of $500 \mathrm{ml} \mathrm{min}^{-1}$ and $1000 \mathrm{ml} \mathrm{min}^{-1}$ respectively.

\section{Results and discussions}

\subsection{Mechanical properties of the carbon paper}

The trend in the mechanical properties of the samples is shown in Fig. 3, where the solid symbols represent the flexural strength and hollow symbols represent flexural modulus. The data seems to be somewhat scatted as the measurements were carried out for a number of prepared samples of each configuration. As shown in Fig. 3a the flexural strength of the carbon paper increases with increasing amount of CNTs from 0 to $0.05 \%$. This is because the incorporation of carbon nanotubes having high aspect ratio and high strength ( $\sim 60 \mathrm{GPa}$ as compared to $3.5 \mathrm{GPa}$ of carbon fiber) effectively increases the load bearing capacity of the carbon paper. Surprisingly further increase in the amount of nanotubes beyond $0.05 \%$ reduces the strength of the composite. The SEM images of the fractured surfaces of the carbon paper samples $\mathrm{C}$ and $\mathrm{E}$ are shown in Fig. 4 and 5 respectively. Fig. $4 \mathrm{a}$ and b shows a strong fiber/ matrix interaction required for high strength composites. On the other hand SEM image of sample E (Fig. 5a and b) shows a lot of fiber pull outs and annular gaps between the fiber and matrix indicating a very weak interaction between the two. This is probably because of their high surface area, CNTs consume most of the resin for its proper wetting, leaving insufficient amount for the fiber to wet. Thus beyond $0.05 \mathrm{vol} \%$ of CNTs, the strength of the composite decreases due to weak fiber/ matrix interaction that does not allow proper load transfer to the fiber. ${ }^{9}$ Fig. 6 shows the dispersed CNTs in the matrix region of sample E.

The flexural modulus of the samples decreases with increasing CNT content as shown in Fig. 3b. Increasing amount of CNTs decreases the fiber matrix interactions and therefore reduces the stiffness and increases the flexibility of the composite paper.

\subsection{Electrical properties of the carbon paper samples}

The in-plane (depicted by solid symbols) and measured through-plane resistivity values (depicted by hollow symbols) of the carbon paper samples is plotted as a function of CNT content in Fig. 7. It should be noted that the measured throughplane resistivity values of the carbon paper include twice the contact resistance between the carbon paper and gold plated copper plated used as contacts.

Because of their high electrical conductivity, CNTs provide a conducting phase in the carbon paper electrode and the 


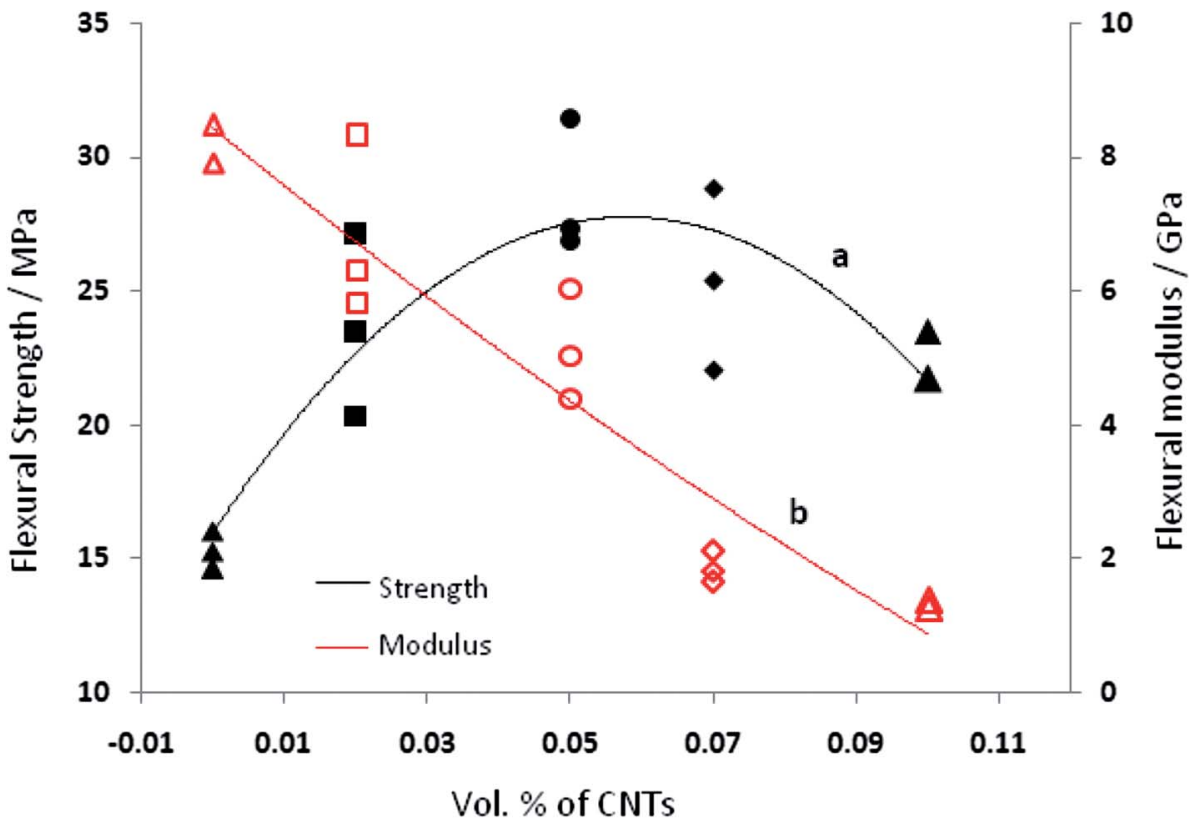

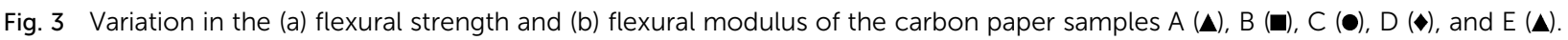

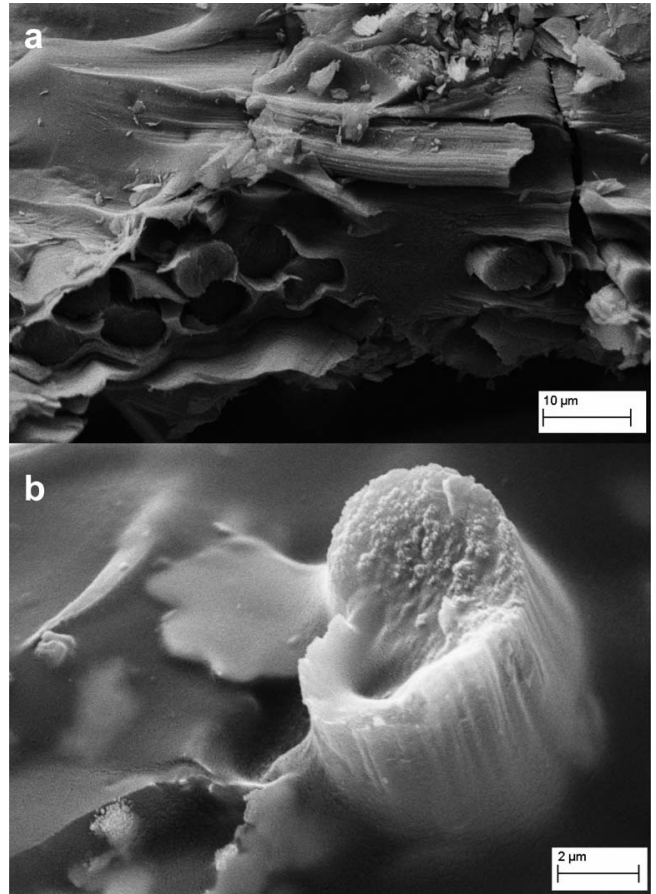

Fig. 4 SEM images of the carbon paper with 0.05 volume \% CNTs.

resistivity of the sample decreases to nearly $30 \%$ as the amount of CNTs is increased from 0 to $0.05 \mathrm{vol} \%$. Conversely the electrical resistivity increases with further CNT incorporation in the sample. As already explained, the high surface area of CNTs result in weak fiber/matrix interactions beyond $0.05 \mathrm{vol} \%$. This has been further explained on the basis of optical studies. The optical micrograph of sample C (Fig. 8a) shows a strong fiber/ matrix interaction (which is clear from the columnar type of

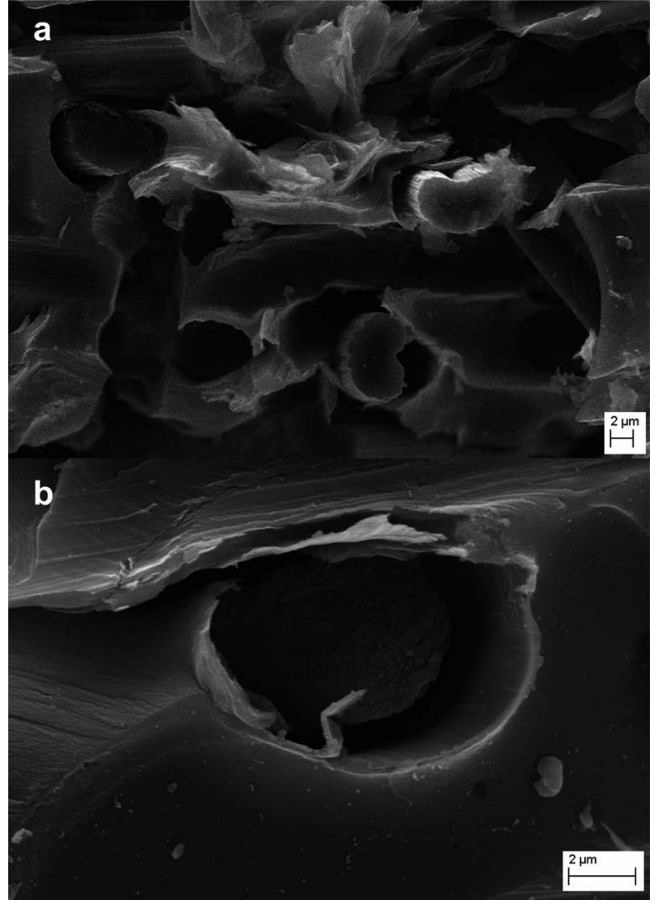

Fig. 5 SEM images of the carbon paper with 0.10 volume \% CNTs.

micro texture) with a highly graphitized matrix as is clear from the anisotropy in the matrix region. With increasing amount of CNT (Fig. 8b and c) annular gaps appear at the interface region because of which the degree of graphitization of the fiber/matrix interface decreases. ${ }^{9}$ The matrix however appears to be graphitized probably due to the graphitization of the CNT/matrix interface as is clear from the increased degree of anisotropy and the size of the matrix domains. 


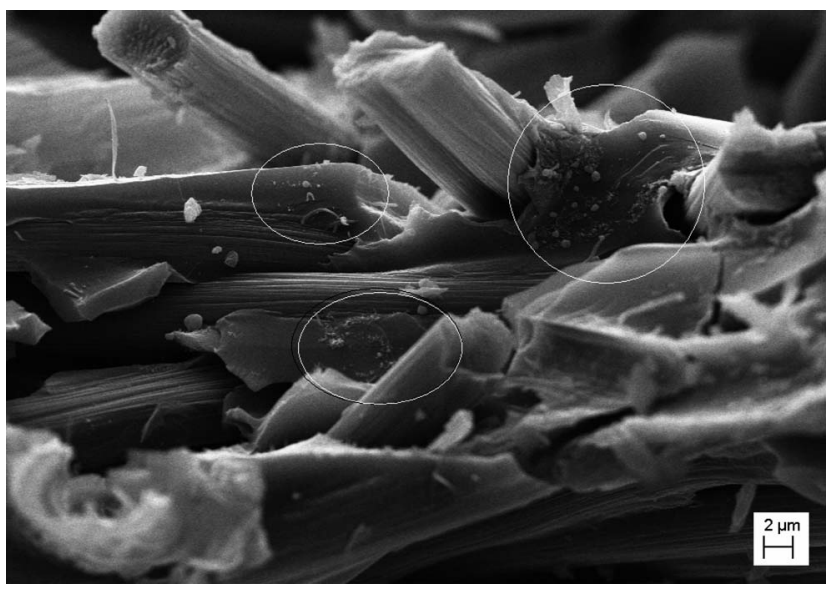

Fig. 6 SEM images of sample E showing CNTs dispersed in the matrix.

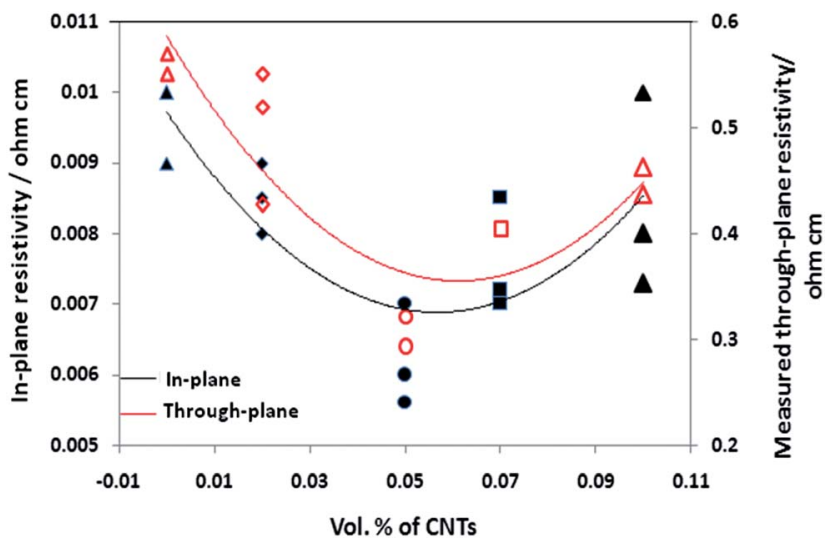

Fig. 7 Variation in the in-plane and measured through-plane resis-

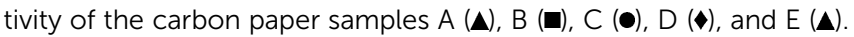

The detail analysis of the matrix area of the carbon paper sample was further carried out by Raman spectroscopy. The Raman mapping of the matrix region of the different samples is shown in Fig. 9. Mapping has been carried out for a number of points in a selected area for each sample. The as prepared carbon paper shows uniformity in the graphitic peak ( $\mathrm{G}$ band) at $1585 \mathrm{~cm}^{-1}$. The $\mathrm{D}$ band at $1350 \mathrm{~cm}^{-1}$ is also clearly visible since the phenolic resin pyrolysis to hard carbon. ${ }^{35}$ In case of sample
$\mathrm{C}$, while the consistency in the $\mathrm{G}$ band is maintained, the $\mathrm{D}$ band almost vanishes which indicates a highly graphitized matrix. As the amount of CNT is further increased (sample D) not only the D band pops up (at places) but at the same time the variation in the intensity of $\mathrm{G}$ band is observed. This indicates certain un-graphitized regions probably due to improper wetting of the high surface area MWCNTs. The non uniformity of the graphitized regions further increases as the amount of CNT is increased to $0.10 \%$. The amount of MWCNTs incorporated in the samples therefore plays a decisive role in matrix graphitization.

Thus the degree of graphitization of both the fiber/matrix interface and the matrix region decreases as the amount of CNTs is increased beyond 0.05 vol\% in the composite thereby leading to increased electrical resistivity. The data in Fig. 7 seems to be scatted as the measurements were carried out for a number of prepared samples of each configuration (A to E). The samples with minimum resistivity (under each pattern) were further employed as electrode for carrying out the unit PEMFC performance.

\subsection{Current-voltage $(j-V)$ performance}

The key performance measure of a fuel cell is the voltage output as a function of the current density drawn, i.e. the polarization curve. The fuel cell polarization curves obtained using carbon paper samples prepared by incorporating different amounts of MWCNT are shown in Fig. 10. From the curve it is clear that the peak power density obtained for the fuel cell increases with increasing amount of MWCNTs in the electrode sample up to $0.05 \mathrm{vol} \%$ (i.e. for sample A to C) from $750 \mathrm{~mW} \mathrm{~cm}^{-2}$ to $880 \mathrm{~mW}$ $\mathrm{cm}^{-2}$, i.e. an increase of nearly $17 \%$. Further incorporation of CNTs into the carbon paper, i.e. upto 0.1 vol\% reduces the fuel cell performance. The peak power density reached by sample $\mathrm{E}$ decreases to nearly $745 \mathrm{~mW} \mathrm{~cm}^{-2}$.

The results have been explained by detailed analysis of the different regions of the polarization curves that allows us to individually separate the various loss contributors The cell potential $(E)$ versus current density $(j)$ data for varying amounts of CNTs in the carbon paper electrode are analyzed by fitting the data to equation:

$$
E=E_{\text {eq }}-\eta_{\text {act }}-\eta_{\text {ohmic }}-\eta_{\text {diff }}
$$
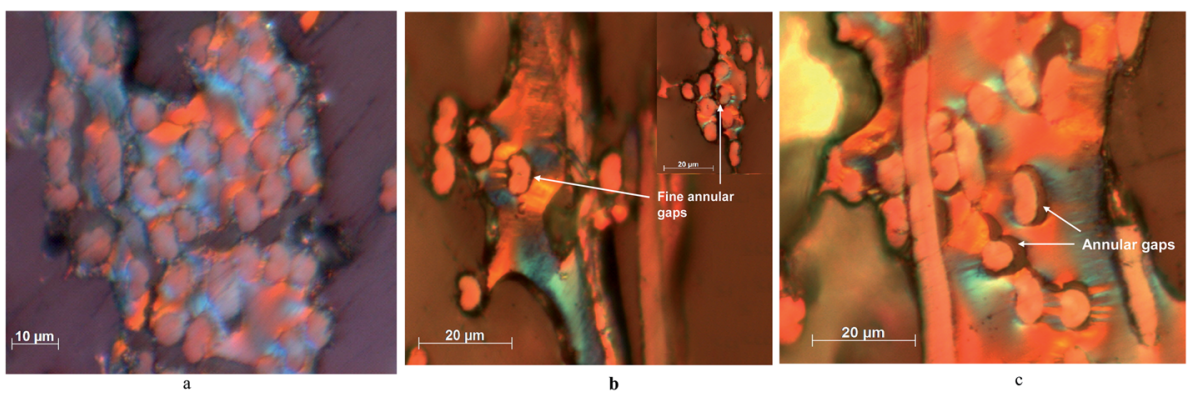

Fig. 8 Optical micrograph of (a) sample C, (b) sample D, and (c) sample E. 

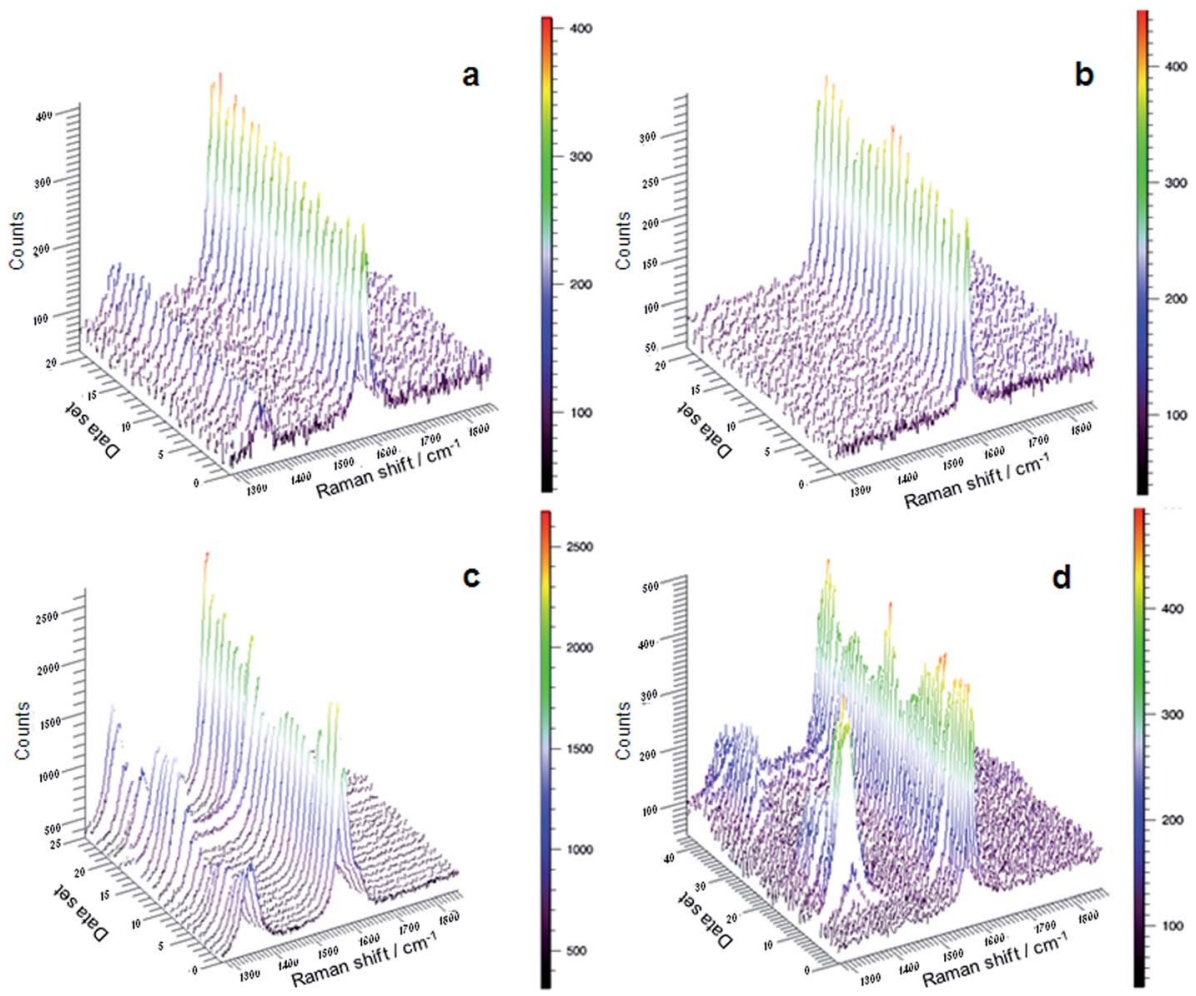

Fig. 9 Raman mapping of the matrix region of the carbon paper samples (a) without CNT, (b) 0.05 vol\% CNT, (c) 0.07 vol\% CNT, and (d) 0.10 vol\% CNT content.

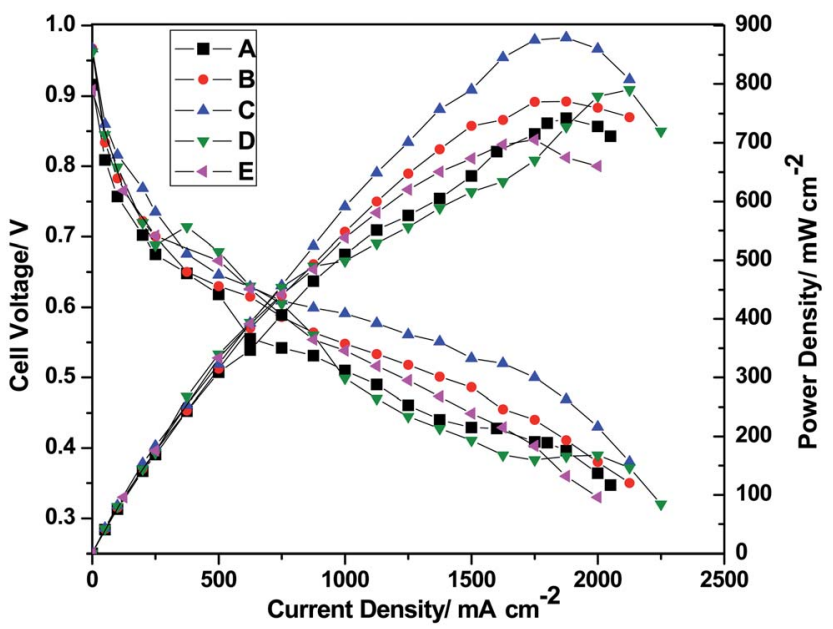

Fig. 10 Comparative current-voltage performance of PEM fuel cell $\left(\mathrm{H}_{2}-\mathrm{O}_{2}\right)$ using carbon papers with different CNT content.

where $E_{\text {eq }}$ is the equilibrium voltage, $\eta_{\text {act }}$ is the activation overpotential due to slow electrode kinetics (of low temperature PEM fuel cell) and is given by

$$
\eta_{\text {act }}=(R T / \alpha n F) \ln \left(j / j_{0}\right)=b \log j-b \log j_{0}
$$

The above eqn (2) is linear of the form $y=a+b x$, where $b(=R T / \alpha n F)$ is the Tafel slope, $j$ is the current density, $j_{o}$ is the exchange current density, $n$ is the number of electrons transferred per mole of reactant, $F$ is Faraday's constant, and $\alpha$ the charge transfer coefficient is the fraction of the overpotential assisting the reaction. Thus slow reaction kinetics leads to an offset in open circuit potential $E_{0}$ by an amount

$$
E_{0}-E_{\mathrm{eq}}=b \log j_{0}
$$

Thus eqn (1) can be written as -

$$
E=E_{0}-\mathrm{b} \log j-j R-\eta_{\text {diff }}\left(\text { where } \eta_{\text {ohmic }}=j R\right)
$$

The electrode kinetic parameters for the cells are summarized in Table 1 while the Tafel plots are shown in Fig. 11. $\alpha$ is calculated from the slope of the Tafel plots while the intercept point represent $\ln \left(j_{0}\right)$. The value of $j_{0.9}$ represents the current density at the cell potential of $0.9 \mathrm{~V}$, known as kinetic current density. The reason for presenting $j$ at a particular cell potential $(0.9 \mathrm{~V})$ along with $j_{0}$ is because even a slight variation in Tafel slope can cause anomalous variation in the values of $j_{0}{ }^{36,37}$ The values of charge transfer coefficient $(\alpha)$ and $j_{0.9}$ increases for samples A to $\mathrm{C}$ whereas the Tafel slopes of the polarization curves decreases. This indicates the feasibility of the reaction with CNT incorporation upto $0.05 \%$. This is probably the result of the increased conductivity and increased surface area, with increasing MWCNT content that results in an increase in the number of possible reaction sites. Similar values of the kinetic parameters have also been reported elsewhere. ${ }^{38,39}$

The cyclic voltammetry (CV) curves of the different carbon paper samples are shown in Fig. 12. The area under the CV 
Table 1 Electrochemical kinetic parameters for the unit PEM fuel cells using carbon paper with different volume \% of CNTs

\begin{tabular}{|c|c|c|c|c|c|c|}
\hline Sample & $E_{0}$ (volts) & $j_{0}\left(\mathrm{~A} \mathrm{~cm}^{-2}\right)$ & $j_{0.9}\left(\mathrm{~mA} \mathrm{~cm}^{-2}\right)$ & $b(\mathrm{~V}$ per decade $)$ & $\alpha$ & $R\left(\Omega \mathrm{cm}^{2}\right)$ \\
\hline $\mathrm{A}$ & 0.9135 & 1.394 & 7.34 & $0.0761 \pm 0.0014$ & 0.1689 & $0.2037 \pm 0.0151$ \\
\hline B & 0.9639 & 1.418 & 25.08 & $0.0719 \pm 0.0024$ & 0.1788 & $0.1610 \pm 0.0094$ \\
\hline $\mathrm{D}$ & 0.9590 & 1.389 & 26.45 & $0.0695 \pm 0.0045$ & 0.1951 & $0.1664 \pm 0.0301$ \\
\hline $\mathrm{E}$ & 0.9070 & 1.380 & 9.75 & $0.0833 \pm 0.0076$ & 0.1549 & $0.2068 \pm 0.0069$ \\
\hline
\end{tabular}

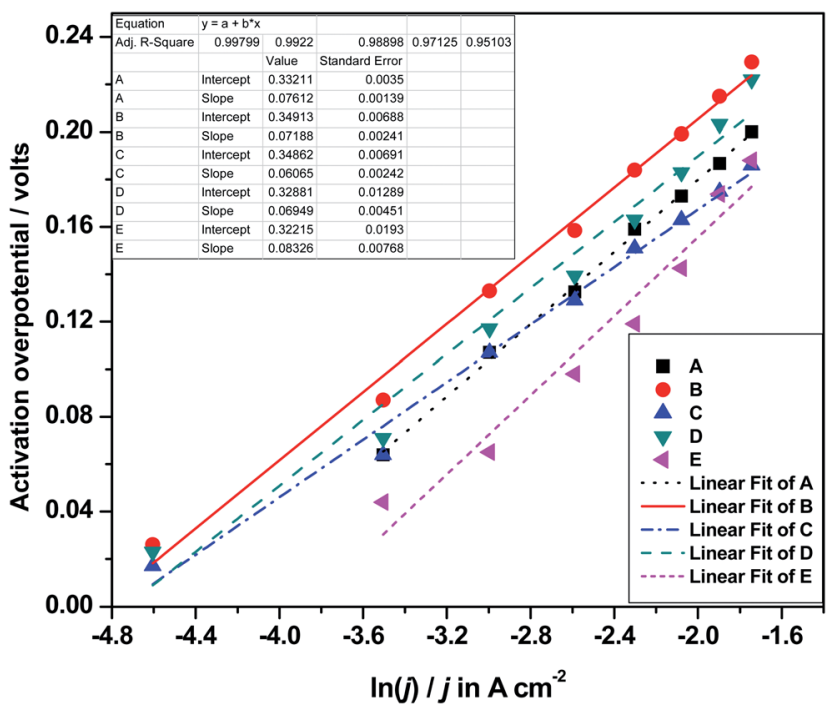

Fig. 11 Tafel plots of the carbon paper with different CNT content.

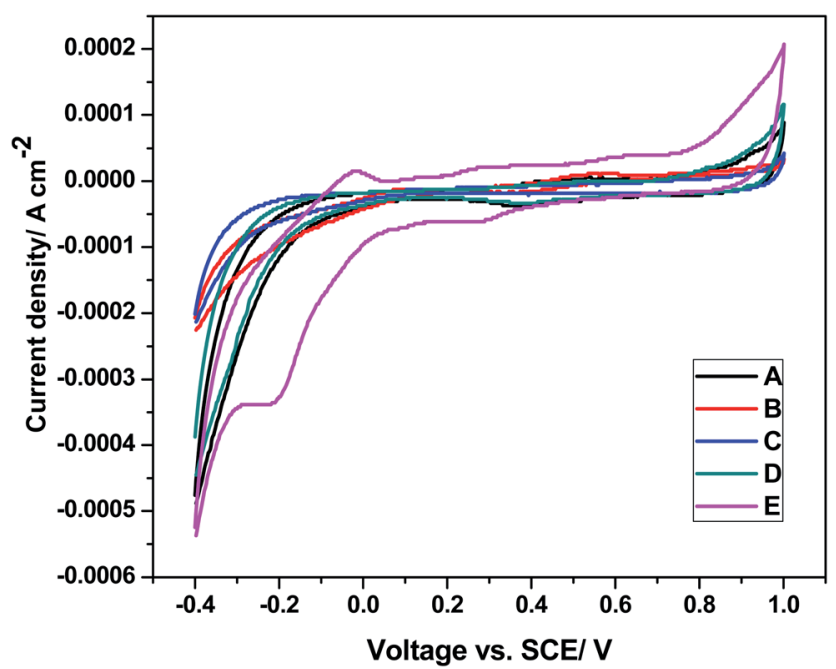

Fig. 12 Cyclic voltammetry curves of carbon paper samples with different CNT contents.

curve decreases for samples with MWCNTs (sample B, C and D) as compared to sample A, indicating that the sample draws less current making it more suitable to be used as an electrode material (owing to its low resistivity). The absence of peaks in the curve during the forward and the reverse voltage sweeps discards the possibility of any active electrochemical reaction
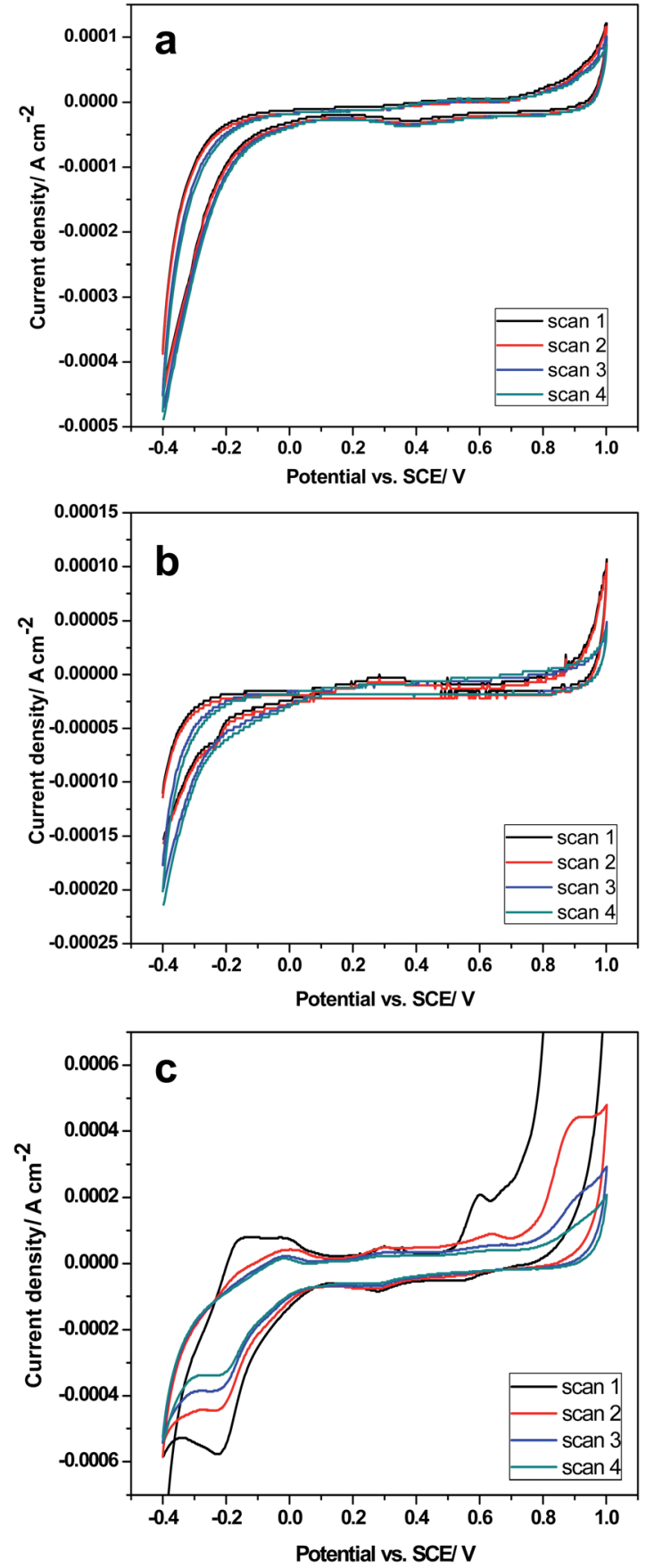

Fig. 13 Four successive scans of the CV curves for (a) sample A, (b) sample $C$, and (c) sample $E$. 
on the surface of the electrode, which could have otherwise drawn the net useful current. However for sample E (with $0.10 \%$ MWCNTs) the area under the curve increases.

The four successive scans for the sample A, C, and E is shown in Fig. 13 (a, b, and c respectively). The overlapping curves for sample A and $\mathrm{C}$ indicates a stable and defect free sample for electrode application. The successive scans of sample $\mathrm{E}$ however show a reduction in the current peaks as well as area under the curve, which in itself indicates the instability of the sample probably due to the presence of impurities. These may be the un-wetted or un-dispersed MWCNTs that can leach out into the electrolyte with successive scans. During the operation of fuel cell the leaching out of the electrode material may be the probable reason for cell degradation.

$\eta_{\text {ohmic }}$ in eqn (1) is the overpotential due to ohmic resistances in the cell and determines the fuel cell resistance (responsible for the ohmic polarization). The slope of the curve (shown in Table 1) decreases with increasing MWCNT content from sample $\mathrm{A}$ to $\mathrm{C}$ but further increases. As the current produced by fuel cell flows serially through the various cell components, the total fuel cell resistance is the sum of all the individual resistance contributors (i.e. flow structures, electrode, membrane). ${ }^{40}$ With other factors remaining the same the electrical behavior of the fuel cell follows that of the carbon paper.

$\eta_{\text {diff }}$ in eqn (2) is the concentration polarization due to poor mass transport. The diffusion flux of reactants to the catalyst layer (or of product away from the catalyst layer) is inversely proportional to the electrode thickness, ${ }^{\mathbf{4 1 , 4 2}}$ and it has been shown that increasing thickness of carbon paper leads to mass transport problems and lower values of limiting current density. ${ }^{42}$ As shown in Fig. 14 the thickness of the carbon paper samples increases with increasing amount of CNTs probably due to swelling of the resin by CNT incorporation. However from Fig. 10 it is clear that neither the mass transport region is much affected, nor the limiting current density decrease despite increasing thickness. This is because the hydrophobic phase in

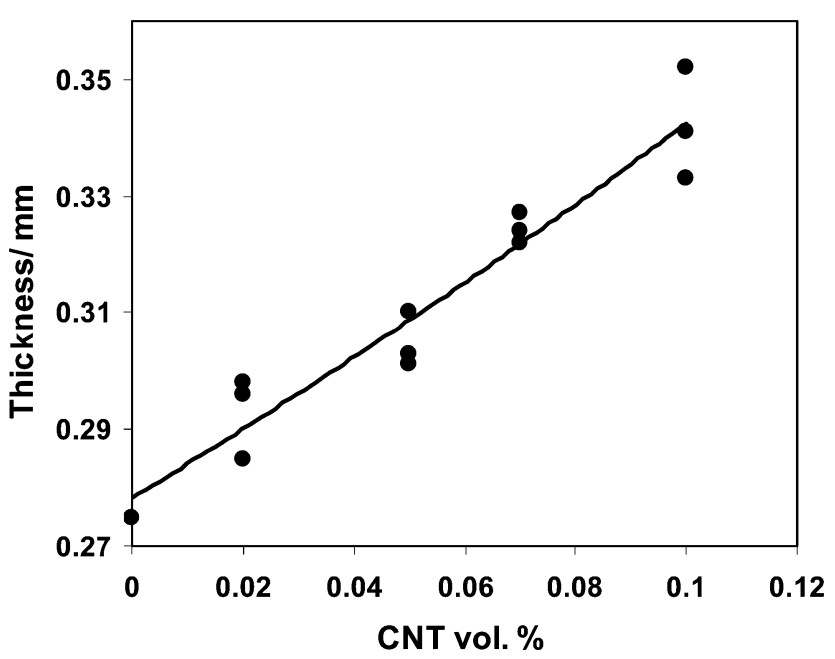

Fig. 14 Variation in the thickness of the carbon paper with different CNT content. the form of CNTs introduced in the carbon paper helps in reducing the probability of flooding thus reducing the diffusion polarization. The existing method of achieving hydrophobicity is by using Teflon which in turn is electrically resistive.

The unit fuel cell performance was also carried out with air as oxidant. As shown in Fig. 15 it follows the same trend with maximum power density of $394 \mathrm{~mW} \mathrm{~cm}^{-2}$ obtained with 0.05 vol\% MWCNTs.

Fig. 16 and 17 shows the comparative unit PEM fuel cell performance, employing carbon paper sample $\mathrm{C}$ and commercially available standard Toray carbon paper (Japan) with $0.5 \mathrm{mg} \mathrm{cm}^{-2}$ and $0.3 \mathrm{mg} \mathrm{cm}^{-2} \mathrm{Pt}$ loadings (on both electrodes) respectively while maintaining identical testing conditions. The peak power density obtained from fuel cell with carbon paper $\mathrm{C}$ is $880 \mathrm{~mW} \mathrm{~cm}^{-2}$ and $814 \mathrm{~mW} \mathrm{~cm}^{-2}$ an increase of nearly $25 \%$ as compared to $700 \mathrm{~mW} \mathrm{~cm} \mathrm{~cm}^{-2}$ and $655 \mathrm{~mW} \mathrm{~cm}^{-2}$ obtained for

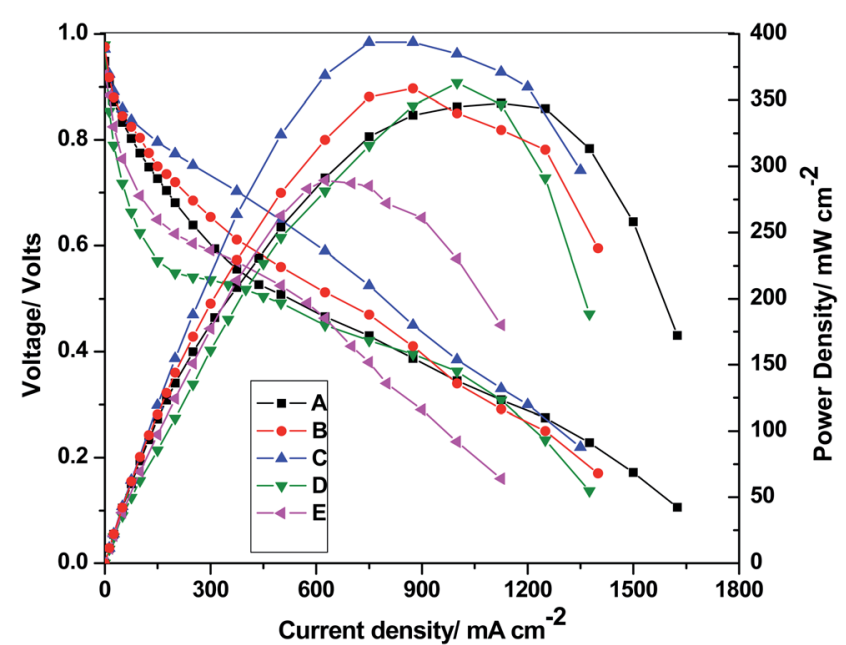

Fig. 15 Comparative current-voltage performance of PEM fuel cell $\left(\mathrm{H}_{2}\right.$-air) using carbon papers with different CNT content.

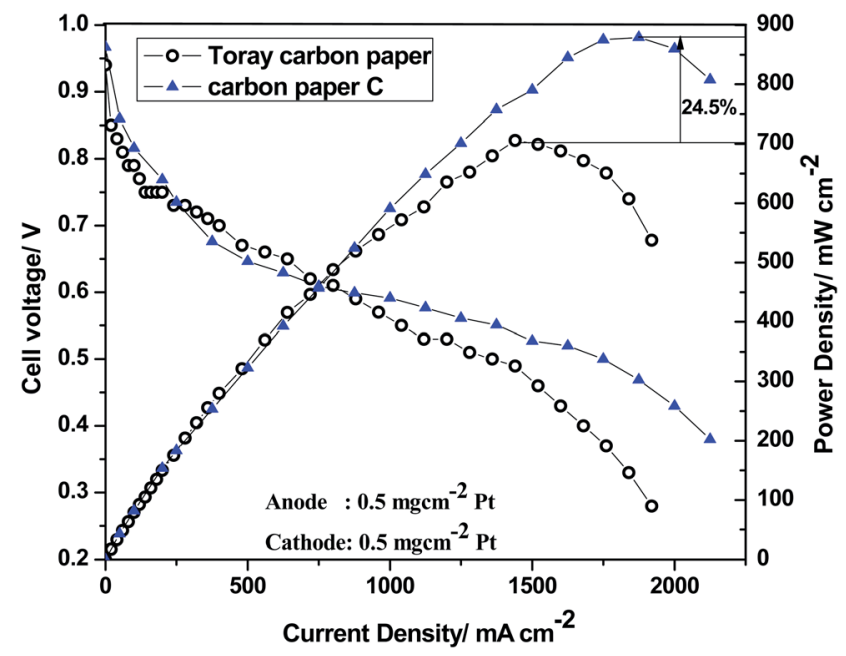

Fig. 16 Comparative current-voltage performance of PEM fuel cell using NPL carbon paper sample $C$ and Toray carbon paper, Japan (with $0.5 \mathrm{mg} \mathrm{cm}^{-2}$ Pt content). 


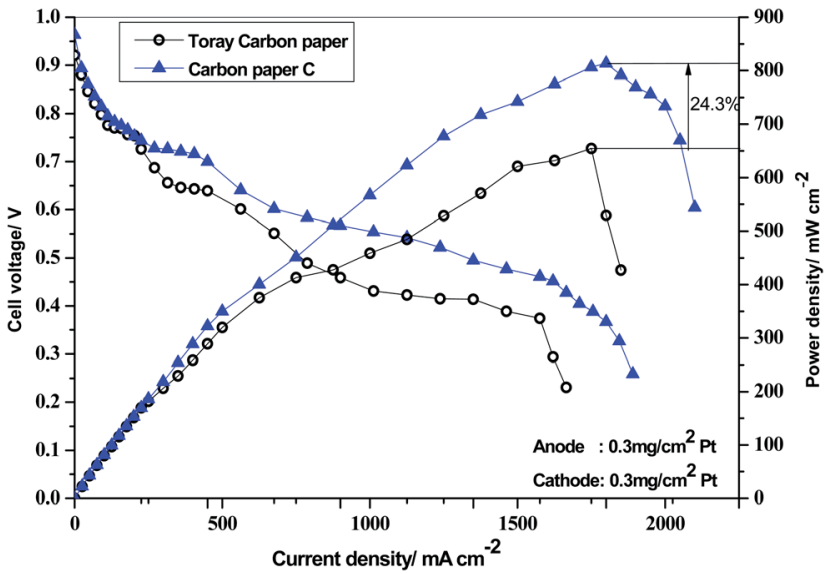

Fig. 17 Comparative current-voltage performance of PEM fuel cell using NPL carbon paper sample $\mathrm{C}$ and Toray carbon paper, Japan (with $0.3 \mathrm{mg} \mathrm{cm}^{-2}$ Pt content).

Toray paper. It is noteworthy that a hike in performance of nearly $16 \%$ has been achieved even with $40 \%$ reduced $\mathrm{Pt}$ loading, thus providing a cost competitive technology.

\section{Conclusions}

A technique of incorporating carbon nanotube (CNT) in the carbon paper has been developed. Sample characterization and fuel cell performance studies illustrate the manner in which a nano material in definite quantity work wonders to achieve high power density. By analyzing the different regions of polarization curves, it was found that improved fuel cell performance is due to; (i) reduction in the activation polarization due to the increase in reaction kinetics because of the high surface area of CNTs; (ii) reduced ohmic polarization as the CNTs provide a graphitic phase in the matrix; and (iii) decrease in the diffusion polarization due to the hydrophobicity introduced by carbon nanotubes that controls flooding of electrode by the water produced in the reaction.

\section{Acknowledgements}

Authors are grateful to the scientists of Central Electrochemical Research Institute (CSIR), Chennai for evaluation of the fuel cell performance. Thanks are also due to Mr R. K. Seth for carrying out the TGA analysis and Mr K. N. Sood and Mr Jai S. Tawale for taking the SEM images. The studies have been carried out under the CSIR funded project 'Development of Next generation Energy Efficient Devices (D-NEED)'.

\section{References}

1 S. Lister and G. McLean, J. Power Sources, 2004, 130, 61.

2 S. M. Haile, Acta Mater., 2003, 51, 5981.

3 R. W. Pekala, S. T. Mayer, J. L. Kaschmitter, and R. C. Morrison, US Pat., 5932, 1999, 185.

4 R. Petricevic, J. Fricke, R. Leuschner and M. Lipinski, US Pat., 6503, 2003, 655.
5 J. L. Kaschmitter, S. T. Mayer and R. W. Pekala, US Pat., 5260, 1993, 855.

6 T. Hirohata and S. Kawakami, US Pat., 6689, 2004, 295.

7 M. A. DeCrescente, G. K. Layden and R. A. Pike, US Pat., 4064, 1977, 207.

8 G. K. Layden, R. A. Pike and M. A. DeCrescente, US Pat., 4080, 1978, 413.

9 R. B. Mathur, P. H. Maheshwari, T. L. Dhami, R. K. Sharma and C. P. Sharma, J. Power Sources, 2006, 161, 790.

10 R. B. Mathur, P. H. Maheshwari, T. L. Dhami and R. P. Tandon, Electrochim. Acta, 2007, 52, 4809.

11 P. H. Maheshwari, R. B. Mathur and T. L. Dhami, Electrochim. Acta, 2008, 54, 655.

12 E. T. Thostenson, Z. Ren and T. W. Chou, Compos. Sci. Technol., 2001, 61, 1899.

13 Q. Wang, J. Dai, W. Li and Z. Wei, Compos. Sci. Technol., 2008, 68, 1644.

14 P. Kim, L. Shi, A. Majumdar and P. L. McEuen, Phys. Rev. Lett., 2001, 87, 215502.

15 X. Zhi-yong, J. Gu-yin, Z. Min, S. Zhe-an, Z. Ming-yu, C. Jianxun, H. Qi-zhong and T. Nonferr, Trans. Nonferrous Met. Soc. China, 2010, 20, 1412.

16 X. Wang, M. Waje and Y. Yan, Electrochem. Solid-State Lett., 2005, 8(1), 42.

17 C. Wang, M. Waje, X. Wang, J. M. Tang, R. C. Haddon and Y. Yan, Nano Lett., 2004, 4(2), 345.

18 M. S. Saha, R. Li, X. Sun and S. Ye, Electrochem. Commun., 2009, 11(2), 438.

19 Y. Chen, J. Wang, H. Liu, R. Li, X. Sun, S. Ye and S. Knights, Electrochem. Commun., 2009, 11(10), 2071.

20 V. Kamavaram, V. Veddu and A. M. Kannan, J. Power Sources, 2009, 188(1), 51.

21 S. Saminathan, V. Kamavaram, V. Veddu and A. M. Kannan, Int. J. Hydrogen Energy, 2009, 34(9), 3838.

22 Z. Tang, C. K. Poh, Z. Tian, J. Lin, H. Y. Ng and D. H. C. Chua, Electrochim. Acta, 2011, 56(11), 4327.

23 Z. Liu, L. Gan, L. Hong, W. Chen and J. Lee, J. Power Sources, 2005, 139, 73.

24 Z. Tang, H. Ng, J. Lin, A. Wee and D. Chuaa, J. Electrochem. Soc., 2010, 157, 245.

25 B. Fang, J. M. Kim, M. Kim and J. S. Yu, J. Electrochem. Soc., 2009, 21, 789.

26 Y. Shao, G. Yin, Y. Gao and P. Shi, J. Electrochem. Soc., 2006, 153, 1093.

27 M. S. Saha, R. Li and X. Sun, J. Power Sources, 2008, 177, 314. 28 Z. Liu, X. Lin, J. Yang Lee, W. Zhang, M. Han and L. Gan, Langmuir, 2002, 18, 4054.

29 S. Maass, F. Finsterwalder, G. Frank, R. Hartmann and C. Merten, J. Power Sources, 2008, 176, 444.

$30 \mathrm{~K}$. Lee, J. Zhang, H. Wang and D. Wilikinson, J. Appl. Electrochem., 2006, 36, 507.

31 A. Guha, W. Lu, T. Zawodzinski and D. Schiraldi, Carbon, 2007, 45, 1506.

32 Y. Mu, H. Liang, J. Hu, L. Jiang and L. Wan, J. Phys. Chem. B, 2005, 109, 22212.

33 P. H. Maheshwari, R. Singh and R. B. Mathur, Mater. Chem. Phys., 2012, 134, 412. 
34 R. Saito, M. Hofman, G. Dresselhaus, A. Jorio and M. S. Dresselhaus, Adv. Phys., 2011, 60(3), 413.

35 E. Fitzer, W. Schaefer and S. Yamada, Carbon, 1969, 7, 643.

36 E. A. Ticianelli, C. R. Derouin and S. Srinivasan, J. Electroanal. Chem., 1988, 251, 275.

37 J. Murphy, G. D. Hitchens and D. J. Manko, J. Power Sources, 1994, 47, 353.

38 G. Selvarani, A. K. Sahu, N. A. Choudhury, P. Sridhar, S. Pitchumani and A. K. Shukla, Electrochim. Acta, 2007, 52, 4871 .
39 K. Suárez-Alcántara, A. Rodríguez-Castellanos, R. Dante and O. Solorza-Feria, J. Power Sources, 2006, 157(1), 114.

40 R. P. O'Hayre, in Fuel Cell Fundamentals, ed. S. W. Cha, W. Colella and F. B. Prinz, John Wiley \& Sons Inc, New York, 2006, ch. 5, pp. 137-168.

41 F. Barbir, in PEM Fuel Cells: Theory and Practice, Elsevier, Burlington, 2005, ch. 3, pp. 33-72.

42 P. H. Maheshwari, R. Singh and R. B. Mathur, J. Electroanal. Chem., 2012, 673, 32. 